\title{
Dispositivos poéticos para nuevos sentidos sobre el trabajo y la cultura*
}

\author{
Alicia K. Valente* \\ Resumen \\ En este trabajo se abordarán algunas prácticas artísticas \\ entendidas como parte de la construcción de procesos \\ colectivos. De forma particular se trabajará a partir de las \\ imágenes plasmadas en dos murales realizados en la fachada \\ del Centro Social y Cultural Olga Vázquez, un espacio \\ autónomo de la ciudad de La Plata. A partir de estas imágenes \\ y poniendo en juego diferentes repertorios poéticos, se \\ explicitaron concepciones disruptivas sobre el trabajo y la \\ cultura, así como formas de reinstauración del vínculo social y \\ afectivo, ligadas principalmente a nuevas formas políticas y \\ sociales postcrisis del 2001 en Argentina. \\ Se buscará dar cuenta de diferentes aspectos de dichos \\ murales, quiénes los realizaron y en qué contextos. Por otra \\ parte, serán también abordados a partir de la noción de \\ dispositivo, y en relación con una nueva visualidad urbana, por \\ tratarse de imágenes que ocupan los muros externos del \\ inmueble y, de este modo, participan del espacio público.
}

* Artículo recibido el 1 de julio de 2014. Aceptado el 31 de agosto de 2014.

* Alicia K. Valente es Profesora y Licenciada en Artes Plásticas; Maestranda en Estética y Teoría de las Artes; Becaria de investigación con el proyecto: "Prácticas artístico-culturales en contextos de autogestión. Los centros culturales independientes de la ciudad de La Plata" del Instituto de Historia del Arte Argentino y Americano (IHAAyA) de la Facultad de Bellas Artes (FBA). Universidad Nacional de La Plata (UNLP). Correo electrónico: alikavaente@gmail.com 


\section{Palabras clave}

Imagen - Dispositivos poéticos - Trabajo - Cultura.

\section{Abstract}

The aim of this paper is to address some artistic practices as part of the construction of collective processes. In particular we will research the images which appears on two murals on the facade of the Cultural and Social Center "Olga Vazquez", an autonomous cultural center of La Plata city. Bringing different repertoires of poetic actions, through them were showed disruptive ideas about the meaning of work and culture. And also were spelled methods of rebuilding social and emotional ties; mainly related to new ways of polítical and social practices after 2001 Argentinian crisis.

Efforts will be made to report different aspects of these murals, e.g. by who was performed and in which historical and social context. They are also addressed from the notion of device, being in relation to a new urban visuality, as the images are located on the front wall of the property involved the space of the street and the city.

\section{Keywords}

Image - Poetic devices - Work - Culture.

\section{Introducción}

En este trabajo se realizará un estudio de dos murales realizados sucesivamente en la fachada del Centro Social y Cultural Olga Vázquez (a partir de ahora CSCOV). Se trata de un espacio cultural autónomo, que funciona desde el año 2003 en la ciudad de La Plata, Argentina, fuertemente vinculado a los procesos colectivos y a los movimientos sociales surgidos al calor de la crisis social, política e institucional del $2001^{1}$ en Argentina. Desde su surgimiento el CSCOV ocupó un inmueble abandonado para ser reactivado desarrollando diversas actividades abiertas a la comunidad, entre otras cosas alberga una biblioteca popular y una radio comunitaria, desarrolla cooperativas y

\footnotetext{
${ }^{1}$ Sobre la década neoliberal del 90 y la crisis de 2001 en Argentina ver: Maristella Svampa La sociedad excluyente. La Argentina bajo el signo del neoliberalismo y Raúl Zibecchi Genealogía de la revuelta. Argentina: la sociedad en movimiento.
} 
proyectos productivos de trabajo, se dictan talleres artísticos y de oficio, funciona como lugar de reunión de colectivos artísticos y movimientos políticos y sociales. ${ }^{2}$

Para realizar este análisis se hará referencia a las disputas público/privado en el ámbito urbano, así como también las nuevas formas de trabajo colectivo y colaborativo que se gestaron a luz de un contexto de precariedad e inestabilidad. Se describirán en rasgos generales en qué consisten las prácticas que se desarrollan en el Centro Cultural, para, a partir de ellas, analizar los murales de la fachada. Se buscará indagar en los repertorios poéticos desplegados en dichos murales entendiéndolos como manifiestos visuales que dialogan con las construcciones que se desarrollan al interior del CSCOV, en particular las que tienen que ver con nuevos sentidos en torno al trabajo y la cultura.

\section{Trabajo autogestivo y cultura popular}

Con el modelo excluyente del neoliberalismo (Svampa, 2005), se profundizaron lógicas de empobrecimiento y exclusión social que comenzaron en la década del 70 durante la última dictadura militar, con formas de flexibilización y precarización laboral, el aumento de las desigualdades sociales, una política general de vaciamiento del Estado, con gran estímulo a las inversiones del capital extranjero y las empresas privadas. De este modo, se produjo un desfinanciamiento de las instituciones públicas que garantizaban a la población el acceso a factores vitales como salud, educación, trabajo y seguridad social. Se produjo también un decaimiento brusco de la clase media, y un empobrecimiento generalizado de las clases bajas.

La despolitización y la naturalización de las relaciones sociales contribuyó a la construcción de "subjetividades neoliberales", es decir, un modo particular de hacer y ser en sociedad basado en el individualismo, el consumismo, la competencia, la fragmentación de las identidades, la resignación. (García Guerreiro, 2010, p. 78)

El estallido del 2001 fue el punto de inflexión donde comenzaron a cobrar mayor visibilidad una variedad de luchas y prácticas de resistencia que se venían gestando ya durante la década anterior. Como destaca Lechner (2002), la política entendida como práctica ciudadana se traspasa hacia formas de la vida social, lo cual se explicitó durante el transcurso de los años de poscrisis, en el surgimiento de nuevos tipos de asociaciones, y la construcción de formas alternativas de organización. Así surgieron las asambleas barriales, los clubes de trueque, las fábricas recuperadas, las prácticas colectivas de artivismo ${ }^{3}$, entre otras. Sobre todo se recupera la noción de trabajo en colectivo, o colaborativo, como principal estrategia para enfrentar la crisis.

\footnotetext{
${ }^{2}$ Si bien el CSCOV sigue funcionando en la actualidad este trabajo alude a las prácticas desarrolladas hasta el año 2012.

${ }^{3}$ Término que combina las palabras arte y activismo.
} 
Así también, en ese contexto, y muchas veces como forma de prolongar experiencias que se gestaron en los años más álgidos, nacen muchos espacios y centros culturales ${ }^{4}$ que insertan sus prácticas en estrategias que exceden el marco de lo estrictamente cultural y "remiten también al lento alumbramiento de nuevas esferas de lo público y formas nuevas de la imaginación y la creatividad social" (Barbero, 2010, p. XXX).

El CSCOV, de la ciudad de La Plata, es un espacio vinculado a los movimientos sociales y a prácticas hijas del 2001. En el año 2003, se realizó la ocupación de un inmueble donde funcionó un emprendimiento educativo privado que fue mandado a quiebra y cerrado por sus dueños, en una zona cada vez más disputada por los emprendimientos inmobiliarios. El inmueble estuvo vacío y abandonado por años, y la ocupación del mismo se realizó en sintonía con otras experiencias de recuperación de espacios ociosos para el desarrollo de actividades culturales y comunitarias. Durante varios años el CSCOV resistió sucesivos embates de desalojo, y se mantuvo como un espacio de creación y reunión colectiva, mientras alrededor se multiplicaban grandes edificios de departamentos y lucrativos emprendimientos inmobiliarios.

Como se mencionó antes, en este espacio funcionan múltiples actividades que van desde emprendimientos autogestionados y cooperativas de trabajo (entre otros, hubo y/o hay una cooperativa de trabajo textil, una pizzería, una imprenta, una cooperativa de herreros, un local de la Red de Comercio Justo donde se comercializa la producción de trabajadores autónomos de la zona), escuelas de oficios, prácticas educativas alternativas y de educación popular, una radio comunitaria, una biblioteca y diversas expresiones artísticas y culturales. Es en sí mismo un espacio que reúne una serie de prácticas disímiles, pero que tienen puntos de vinculación entre ellas. Resulta evidente que uno de los aspectos más importantes que atraviesa todas las prácticas que tienen lugar en el centro social y cultural, y que es lo que lo distingue quizá de otros espacios similares, tiene que ver con el trabajo, principalmente de tipo colectivo y las cooperativas autogestionadas.

En este marco

...el trabajo, la propiedad de los medios de producción, el mercado, y las relaciones sociales de producción, intercambio y consumo son resignificadas. En la producción, el trabajo sin patrón, las herramientas de propiedad compartida, el trabajo colectivo, el cuestionamiento al uso de ciertas tecnologías y la autogestión han implicado fuertes cambios en los mundos de vida de sus protagonistas -incluso en su autoestima- aportando a la construcción de nuevas subjetividades y sociabilidades

\footnotetext{
${ }^{4}$ Ana Wortman hace este análisis para el caso de Capital Federal, donde las asambleas barriales surgidas con el estallido del 2001 se constituyeron luego en espacios o centros culturales con lugar físico determinado. Se considera que en el caso de la ciudad de La Plata, la continuidad no fue tan directa pero que igualmente muchos individuos y colectivos continuaron sus prácticas en experiencias de este tipo.
} 
basadas en la cooperación y el mutuo reconocimiento. (García Guerreiro, 2010, p. 79)

Además del trabajo autogestivo, el CSCOV desarrolla también múltiples actividades vinculadas a lo artístico y cultural. Como se mencionaba anteriormente, el factor cultural fue predominante en las prácticas que surgieron a partir del 2001, tornándose un campo privilegiado de resistencia y de batalla.

Cultura, sin embargo, es un término complejo y polisémico. En este sentido, Raymond Williams se pregunta: "¿Comprendemos la cultura como las artes, como un sistema de significados y valores o como un estilo de vida global y su relación con la sociedad y la economía?" (Williams, 2000a, p.23). Este autor señala que en distintas épocas el término cultura designó tanto un objeto (los productos culturales), como un proceso (la cultura de la tierra, de los animales, etc.). Así, se habla de cultura como el conjunto de prácticas y producciones artísticas, o como un concepto antropológico y sociológico, es decir, se habla de cultura con un "sentido social general" (Williams, 2000a, p.28), donde se hace necesario hablar de culturas más que de cultura. En este sentido cultura "no es sólo un corpus de trabajo intelectual e imaginativo; también es, y esencialmente, todo un modo de vida" (Williams, 2000, p. 265).

Esta última acepción del término permitió el surgimiento de "un nuevo imaginario en el que [...] adquiere estatus de cultura lo que viene del pueblo" y por tanto "la necesidad de aceptar la existencia de una pluralidad de culturas, esto es, de diferentes modos de configuración de la vida social" (Barbero, 2010, p. 7). En este marco se encuadrarían los usos del término cultura para los integrantes del CSCOV, ya que desde este espacio referencian el término cultura en tanto "cultura popular", disputándole el monopolio de esta a las clases dominantes ya que, se sostiene desde estos espacios, también el pueblo hace cultura. ${ }^{5}$

De este modo, Barbero también considera que se tiende a relacionar lo popular con la tradición, cuya autonomía estaría garantizada por una separación total que le impida ser alcanzada y contaminada por la cultura oficial y hegemónica, en una "redefinición de lo popular por su oposición a lo hegemónico" (García Canclini). Pero, explica Barbero, que de esta forma se niega "el proceso histórico de formación de lo popular y el sentido social de las diferencias culturales: la exclusión, la complicidad, la dominación, la impugnación" (Barbero, 2010, p. 10) y por tanto las lógicas que determinan la reubicación del concepto cultura en el campo político, como un campo de tensión donde se disputan los significados que generarían sentidos de pertenencia común. Así, hay autores que, en lugar de negar radicalmente el término, lo reivindican "como espacio no sólo de manipulación, sino de conflicto, y la posibilidad entonces de

\footnotetext{
${ }^{5}$ Nombre dado a una iniciativa de cultura comunitaria, autogestiva e independiente que abarca diferentes países de Latinoamérica. Fuente: http://www.pueblohacecultura.org.ar/
} 
transformar en medios de liberación las diferentes expresiones o prácticas culturales" (Barbero, 2000, p. 14). De ahí el potencial que radicaría en hablar de lo cultural, entendido como el campo de batalla por el sentido, donde los diferentes grupos o colectivos pugnan por legitimar sus prácticas.

\section{Nueva visualidad urbana}

Los avances del neoliberalismo que se mencionaron antes, instauraron un debilitamiento de lo público y la pérdida de instancias de ciudadanía, con la creciente multiplicación de lo que Marc Augé llamó de "no lugares", esto es, lugares de paso, espacios del anonimato: redes de autopistas, shoppings, aeropuertos, terminales, etc. Diferentes a los lugares, que son espacios para el vínculo, lo relacional, el ejercicio ciudadano, los "no lugares" de la sociedad contemporánea, son espacios de tránsito, o espacios para el consumo y el ocio programado, que muestran nuevas formas de la relación social regidas exclusivamente por las lógicas del mercado (Augé, 1993). Con una fuerte tendencia a la mercantilización de las relaciones sociales, donde los derechos a la propiedad privada y al rédito económico, echan por tierra cualquier otra noción de derechos: "[...] éste es un mundo en el que la ética neoliberal de un intenso individualismo posesivo y su correspondiente retirada política de las formas de acción colectiva se convierte en el modelo de la socialización humana" (Harvey, 2008, p. 31).

Si la ciudad es la "proyección de la sociedad sobre el terreno" (Lefebvre, 1969, p.75) el espacio público es el lugar donde se ponen en disputa formas diferenciadas, muchas veces antagónicas, de accionar sobre la ciudad. Frente a las prácticas de dominio, es decir, regidas por la búsqueda de una mayor rentabilidad del espacio, vastos sectores de la sociedad buscarán impulsar prácticas de apropiación de distinto tipo, instancias creativas en función de su habitabilidad (Salomone \& Marsonet, 2011). Muchas de estas prácticas son de carácter informal, y encontrarán permanentemente la resistencia de un Estado que busca, a través de la restauración de la formalidad, una forma de control social (Jáuregui, 2008). Esa informalidad se va a establecer en formas novedosas y no oficiales de uso, tanto de los espacios públicos como de los lugares abandonados, los vacíos del imaginario urbano. Frente a una consolidación cada vez mayor de la ciudad formal, la informalidad va proliferando en los intersticios que se producen dentro de los grandes proyectos urbanísticos. Estos espacios que han ido quedando al margen, son zonas potenciales a ser activadas en función de las necesidades de los sujetos que han sido apartados, de alguna forma, de la planificación urbana. "El espacio urbano hoy es el palimpsesto de una continua experimentación de modos de vida en público. Lo que nace no son nuevos espacios públicos, sino nuevas dimensiones de vida y relación en público" (La Varra, 2008, p. 14).

En diciembre de 2001 la cuidad se transformó cobrando nuevas configuraciones signadas por diferentes formas de protesta que se lanzaron al espacio público. La ocupación de plazas, calles y avenidas por parte de las asambleas barriales, grupos de 
trueque, y diferentes expresiones de protesta contra los bancos y las instituciones, hegemonizaron las prácticas sobre el espacio urbano, cambiando radicalmente su aspecto (Giunta, 2009).

Por un lado se observa un proceso en que se quiebra la lógica de repliegue de la vida hacia lo privado, hacia el espacio interior de las casas. ${ }^{6}$ Las jornadas de 2001 van a implicar entonces un giro y una vuelta hacia el espacio urbano y el espacio público ${ }^{7}$, tanto para protestas de todo tipo, prácticas de supervivencia económica (clubes de trueque), instancias de visibilización y nuevas formas de socialización. En los meses posteriores a diciembre de 2001 todos los aspectos de la vida social tenían lugar en la calle.

Por otro lado se observa que "fue un momento en el que la creatividad se mezcló con la protesta. La ironía y el humor, la búsqueda de formas nuevas de hacer visible el eje de las demandas se democratizó" (Giunta, 2009, p. 54). El recurso a producciones artísticas y creativas para lograr visibilidad y repercusión fue una constante, lo que significó la constitución de toda una nueva visualidad en el espacio urbano. Entre otras cosas, los muros empezaron a ser el lienzo sobre el que se plasman las demandas, y también los sueños y proyectos. Surge una proliferación de esténciles (una técnica que permite imprimir una imagen en la pared u otra superficie de forma rápida, y cuyo repertorio visual es, en líneas generales, sintético y de fácil lectura). Así los artistas se lanzan a los muros de distintas ciudades del país para cubrirlos de imágenes que dialogan unas con otras (Giunta, 2009). Junto con los esténciles, también aparecieron las pegatinas, los afiches y el uso del grafiti, además de los murales que ya venían desarrollando los distintos colectivos de artistas, como formas de denuncia y resistencia en un marco de conflictividad social.

Quizá lo que terminó de configurar una nueva visualidad urbana en la ciudad de La Plata, fue el momento, a partir del año 2008, en que el cambio de autoridades municipales comenzó a flexibilizar la normativa "La Plata, Ciudad Limpia". Esta ordenanza (Ordenanza Municipal No9880) fue implementada en el año 2006 y buscaba combatir la contaminación visual urbana, así al mismo tiempo que se retiraban los

\footnotetext{
${ }^{6}$ No solo la vida individual se circunscribe al ámbito privado durante la década del 90, sino también muchas instancias de la vida social, tales como los espacios destinados al ocio y a la recreación, en que el auge de los shopping center, por ejemplo, (entre otros modelos de ocio programado) desplazan a los clubes, las plazas y otras instancias de socialización en público.

${ }^{7}$ En los primeros meses el espacio público recuperado por excelencia fue la calle. Aun así, las actividades y propuestas que fueron surgiendo con el transcurso de los meses excedieron la calle para lanzarse a habitar otras formas de lo público: "El espacio ocupado por estos fenómenos rara vez es "público" en sentido estricto, es el espacio de enclaves infraestructurales, de recintos industriales abandonados, de aparcamientos inutilizados" (La Varra: 2008, p.14). Con esto se propone dar cuenta de una serie de debates que existen alrededor de reducir la concepción de lo público al uso sobre la calle (espacio público urbano paradigmático). Las ocupaciones de inmuebles abandonados llevadas adelante por asambleas barriales o centros culturales son ejemplo de eso, pero también intervenciones en los medios de comunicación, redes sociales, e internet, que aluden a una ampliación de la esfera de lo público.
} 
carteles de mayor tamaño en las calles comerciales, se blanqueaban sistemáticamente los muros de la ciudad. Como se mencionó, con el cambio de autoridades, la medida se flexibilizó considerablemente y los muros fueron ocupados extensamente por una diversidad de artistas que los cubrieron con esténciles, murales, afiches, pegatinas, grafitis y múltiples formas visuales urbanas tal como se observa hoy en día.

\section{Murales, dispositivos, poéticas y políticas}

A continuación, se estudiarán los murales de la fachada del CSCOV, buscando establecer diálogos con las prácticas y las formas organizativas del espacio, así como con el contexto desarrollado en los apartados anteriores.

Entre las características principales de los murales se destacan la monumentalidad, la cual no sólo está dada por el tamaño de la pared sino por cuestiones compositivas de la imagen, y la poliangularidad, que permite romper el espacio plano del muro. Es un trabajo colectivo y cooperativo, caracterizado la mayoría de las veces por generar espacios de participación e inclusión de la comunidad local. (Capasso, 2011, p. 8)

El interés del presente trabajo radica en analizar dichos murales como dispositivos que funcionan a modo de espacio limítrofe, borde o frontera, que a su vez pertenece a las dos dimensiones, al espacio interior del inmueble y al espacio exterior urbano. Estos murales, lejos de cumplir una función decorativa, o incluso de trabajar alguna temática afín al espacio (como muchos otros que se encuentran en paredes del interior de CSCOV) elaboran poéticas que funcionan de forma tal que reflejan las lógicas de las prácticas que se desarrollan dentro, y a su vez en el tejido social de la comunidad, fundamentalmente en torno a nuevos sentidos construidos acerca de la cultura, el trabajo y la producción autogestiva.

Para abordar desde la noción de dispositivo las producciones de imágenes y visualidad es pertinente recurrir a la definición dada por Jacques Aumont, que sostiene que excede la imagen misma, para abarcar toda una serie de determinaciones sociales que hacen a los medios de producción, los modos de circulación y los soportes, pudiendo "situar la noción misma de dispositivo en el interior de la esfera de lo simbólico" (Aumont, 1992, p. 185).

Esta definición puede complementarse con la dada por Gilles Deleuze, quien retomando a Michel Foucault define el dispositivo como "máquinas para hacer ver y para hacer hablar" (Deleuze, 1990, p. 155), las cuales están ligadas a regímenes históricos de visibilidad y de enunciación. "Si hay una historicidad de los dispositivos, ella es la historicidad de los regímenes de luz, pero también la de los regímenes de enunciación" (Deleuze, 1990, p. 156). Dichos regímenes, son los que distribuyen, los que rigen lo visible, y lo no visible, lo enunciable y lo no enunciable. 
Giorgio Agamben retomará la noción de dispositivo de Foucault como lugar de invención de una subjetivación:

Llamaré literalmente dispositivo cualquier cosa que tenga de algún modo la capacidad de capturar, orientar, determinar, interceptar, modelar, controlar y asegurar los gestos, las conductas, las opiniones y los discursos de los seres vivientes. No solamente, por lo tanto, las prisiones, los manicomios, el panóptico, las escuelas, la confesión, las fábricas, las disciplinas, las medidas jurídicas, etc., cuya conexión con el poder es en cierto sentido evidente, sino también la lapicera, la escritura, la literatura, la filosofía, la agricultura, el cigarrillo, la navegación, las computadoras, los celulares y por qué no- el lenguaje mismo, que es quizás el más antiguo de los dispositivos. (Agamben, 2008, p. 38-39)

En este sentido, la noción de dispositivo desarrollada por Agamben, es aquella donde se amplía la conceptualización de zona de control de un estado disciplinar, para abordar todo lo que se constituya en un mecanismo productor de subjetividad. Como destacan Félix Guattari y Suely Rolnik:

...la cultura de masas produce individuos: individuos normalizados, articulados unos con otros según sistemas jerárquicos, sistemas de valores, sistemas de sumisión [...] lo que hay es simplemente producción de subjetividad. No sólo producción de la subjetividad individuada - subjetividad de los individuos sino una producción de subjetividad social que se puede encontrar en todos los niveles de la producción y del consumo. (Guattari \& Rolnik, 2006, p. 29)

Si se retoma aquí esta acepción dada por Agamben, es porque se considera que los dispositivos en casos como los abordados en este trabajo, son susceptibles de entenderse disruptivamente, de entenderse como desarrollan Guattari \& Rolnik (2006) como "procesos de singularización", es decir como formas de "construir modos de sensibilidad, modos de relación con el otro, modos de producción, modos de creatividad que produzcan una subjetividad singular" (Guattari \& Rolnik, 2006, p. 29). Así, los murales de la fachada del CSCOV no constituyen dispositivos en tanto productores de subjetividad social hegemónica, sino por el contrario, en tanto productores de una subjetividad singular y disruptiva.

El CSCOV está ubicado sobre una avenida, ${ }^{8}$ en una zona "absorbida" por el centro de la ciudad, con gran desarrollo de proyectos inmobiliarios, y está cercano al eje comercial de la calle 12 de La Plata. Así, se ha convertido en una avenida con una gran circulación de personas de toda la ciudad, no solo de los habitantes del barrio.

En el año 2007, en el marco de la campaña por el "No al remate" del inmueble, el colectivo Sienvolando ideó un mural para la fachada del CSCOV. Sienvolando se formó en la ciudad de La Plata en el año 2002 y se disolvió a mediados de 2009. Se definían

\footnotetext{
${ }^{8}$ El CSCOV queda en Avenida 60 entre calles 10 y 11, de la ciudad de La Plata.
} 
"como grupo, un conjunto de personas que se unen para ciertas acciones". ${ }^{9}$ Así, buscaban dar cuenta de una formación variable, con un pequeño número de personas que eran motor de las prácticas, pero cuya integración total se conforma según cada acción. En cuanto a la composición del colectivo artístico, algunos eran estudiantes de artes visuales y otros no. Entendían las prácticas artísticas como formas de intervención social, y definían su propia práctica de este modo: "no es tanto una acción artística cuanto una acción política a través de medios estéticos". ${ }^{10}$ Luego de un tiempo comenzaron a articular con organismos y espacios que mantenían diferentes luchas, como la Coordinadora contra la Represión Policial e Institucional (CORREPI), los obreros de la fábrica textil Mafissa, los autoconvocados contra el SIDA, el Frente Popular Darío Santillán, etc. Con muchas de estas organizaciones realizaron trabajos en conjunto, como fue el caso del mural realizado en el CSCOV.

El colectivo que habita el espacio del CSCOV describe el trabajo de Sienvolando en su fachada como un "mural que diseñaron a partir de nuestras prácticas, y que pintamos todos juntos" y que "nos da una mano para explicar quiénes somos, qué hacemos, y de qué forma lo hacemos". ${ }^{11}$ En el mural que se encuentra sobre el portón de chapa de la izquierda se lee "La cultura, el trabajo y los Derechos Humanos no se negocian" una de las consignas del espacio. En primer plano a la derecha de la pared, entre la puerta y la primera ventana de la fachada, se puede ver en gran tamaño la figura de una joven que cubre su cara con una máscara, $y$, empuñando el mango de una soldadora, se encuentra en la tarea de soldar una luna de chapa que sobrepasa el borde superior de la pared. La joven está parada sobre una superficie semicircular, a la manera de los horizontes tomados con las lentes fotográficas llamadas "ojo de pez". El cable de la máquina baja de la mano de la joven y sigue un recorrido hacia la derecha del mural, donde, en segundo plano, vemos unas siluetas de hombres trabajando con palas y otros elementos de la construcción; un poco más atrás otras siluetas hacen movimientos de capoeira. Sobre el horizonte curvo se observan siluetas de casas y árboles. El cable se abre camino por una calle de barrio para llegar finalmente a la soldadora que se encuentra al lado de una máquina de coser y de un bombo de murga, todos sobre una superficie de un plano azul claro, que tiene escrito las actividades que se realizan en el lugar. Arriba, a la izquierda, al lado de la luna de chapa se lee un cartel: "No al remate". Como decían los integrantes del CSCOV, este mural da cuenta de qué actividades tienen lugar en el espacio. Pero sobre todo, da cuenta de una particular búsqueda identitaria, el quiénes somos, y de modos de hacer también particulares, el cómo hacemos. Ambos suponen formas disruptivas a lo establecido, a lo hegemónico,

\footnotetext{
${ }^{9}$ Entrevista al grupo de arte Sienvolando. Por el Colectivo Indymedia La Plata, 2008.

${ }^{10}$ Ibídem

11 "La casa de tod@s". www.elmachete-fpds.blogspot.com.ar/2008/11/csc-olga-vzquez.html.
} 
que se perciben al ver el cable que sale de la soldadora y recorre toda la composición, que enlaza y unifica prácticas artísticas con formas de trabajo, con la silueta de un barrio. Y está la niña, claro, soldando una luna de chapa.

La propiedad colectiva implica nuevos desafíos en la construcción de nuevas relaciones pedagógicas, nuevas formas de producción y nuevos lazos militantes que nos unan en la resistencia. Esos desafíos nos interpelan, y, convertidos en electrones que se aceleran, se excitan y se mezclan dentro del cable amarillo que recorre todas las expresiones, culminan ayudando a la niña herrera del mural, a construir nuestros propios astros como guía. ${ }^{12}$

Así, el qué hacemos es igual a trabajo (autogestivo, cooperativo, sin patrón), arte, cultura (popular). Y el cómo hacemos es igual a colectivo, colaborativo, vincular, relacional, disruptivo, resistente, con alegría.

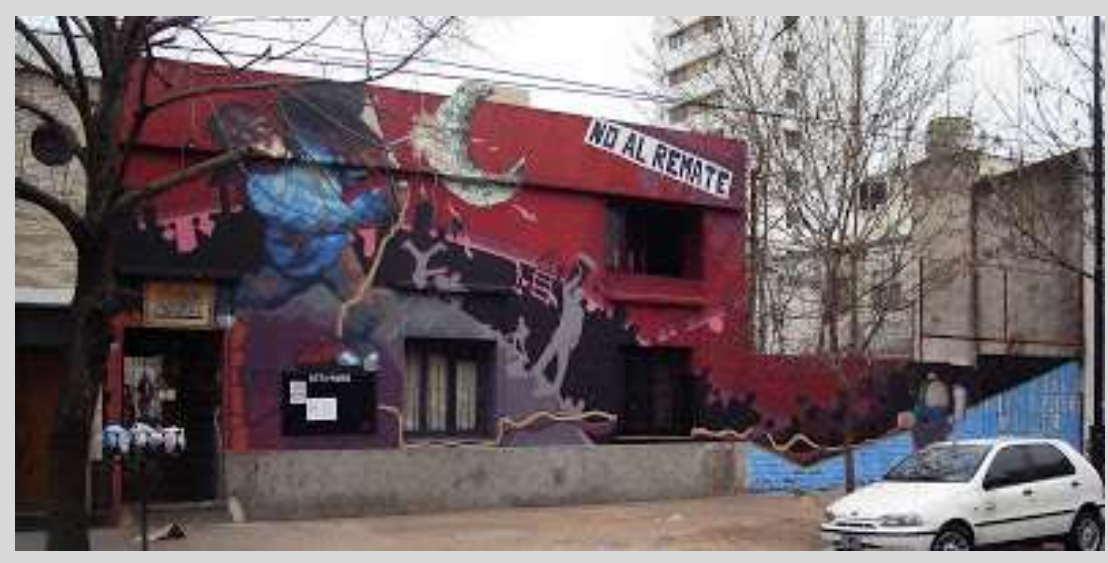

Figura 1: Mural del colectivo Sienvolando realizado en al año 2007. (Disponible en http://sienvolando.blogspot.com.ar/2007/09/centro-social-olaga-vazquez-1-y-2-de.html)

\footnotetext{
12"La casa de tod@s”. www.elmachete-fpds.blogspot.com.ar/2008/11/csc-olga-vzquez.html.
} 


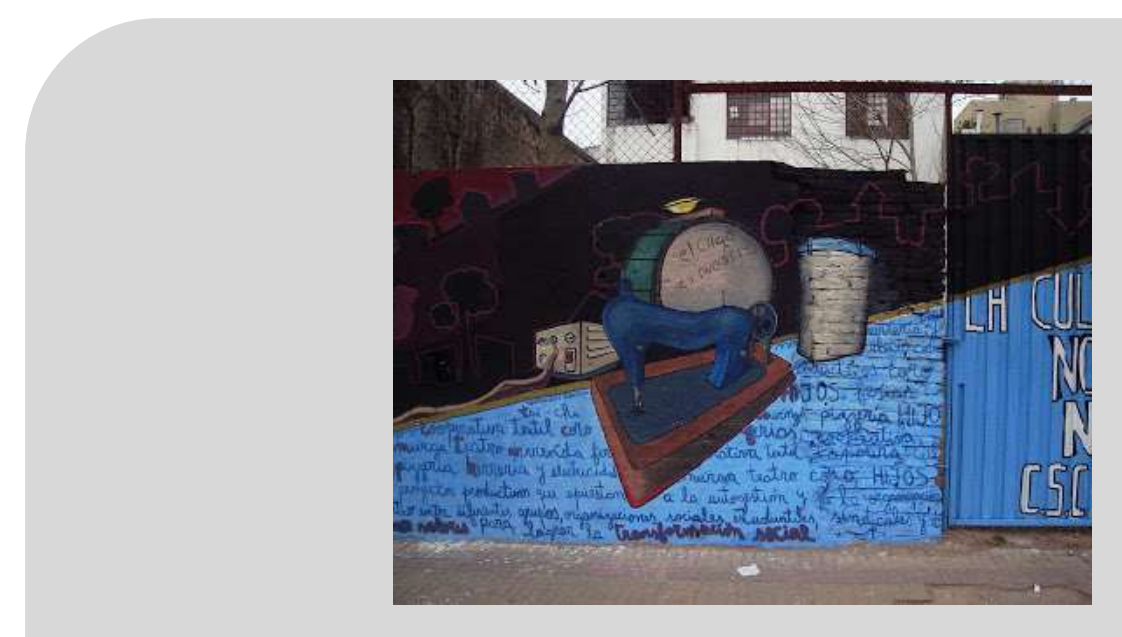

Figura 2: Detalle del mural del colectivo Sienvolando.

(Disponibles en http://sienvolando.blogspot.com.ar/2007/09/centro-social-olaga-vazquez-1-y-2-de.html)

Con los años el mural original sufrió el deterioro. Un nuevo mural se realizó en octubre de 2012, en el marco de ZigZag, ${ }^{13}$ un encuentro latinoamericano de diversas expresiones artísticas que se llevó a cabo en distintos muros, espacios públicos y espacios culturales autónomos de la ciudad. El boceto estuvo a cargo del artista platense Nelson Sosa, y fue realizado de manera colectiva durante varias jornadas en el marco del mencionado encuentro.

Al igual que el mural anterior, el nuevo mural también está realizado a partir de las prácticas que se desarrollan en el espacio. En este caso vemos sobre la puerta que dos manos (y hay una tercera hacia la mitad del mural) empuñan una manigueta de serigrafía ${ }^{14}$ que entinta y cubre de color la pared donde se despliega un barrio de casas de chapas y unas gomas de auto. Se observa así que el inicio de la lectura de la imagen podría encontrarse a la izquierda de la fachada. Entonces, de las gomas desplegadas al costado de un barrio sale el humo que impregna el aire de las rutas cuando hay un "piquete", ${ }^{15}$ pero en este caso en lugar de ser oscuro es de múltiples colores. Las columnas de humo se convierten en la tinta que recoge la manigueta para imprimir "Olga Vázquez". En la imagen se encuentra una alusión a los trabajos en barrios periféricos de la ciudad y como mencionábamos, a los cortes de ruta, principal herramienta de protesta de los movimientos de desocupados surgida durante la

\footnotetext{
${ }^{13}$ Ver: www.haciendozigzag.com.ar

${ }^{14}$ Serigrafía es una técnica de impresión que permite estampar diversas superficies. La manigueta es la herramienta que se utiliza para distribuir la tinta.

${ }^{15}$ El piquete o corte de ruta, fue una de las estrategias desplegadas por los desocupados que recurrieron a interrumpir la circulación quemando gomas de auto en las rutas nacionales y provinciales para lograr dar visibilidad a su reclamo. Sin embargo, "piquete" y "piquetero/a" aluden a mucho más que la modalidad del reclamo, representan la forma de acción colectiva que permitió a amplios sectores desplazados del sistema construir otra pertenencia identitaria. Ver: Svampa, M. "El devenir de las organizaciones piqueteras en Argentina".
} 
década neoliberal. Al calor de esas luchas en los 90 se gestaron espacios y trabajos como los que se desarrollan en este ámbito en la década posterior al 2001.

La imagen que recrea un barrio presenta a todas las casas con su pequeña antena y de todas ellas nace una gran antena que recorre la imagen desde la base hasta perderse en el borde superior de la pared. También se ve un tejido y el nombre y logo del espacio, un "fueguito" color naranja, está pintado con una trama que remite a lo textil. La cooperativa de trabajo textil es una de las primeras que se gestó al interior del CSCOV; y en el año 2011, después de mucho tiempo de trabajo para conseguirlo, se pudo instalar la antena para que transmitiera desde allí mismo una radio comunitaria: Radionauta. ${ }^{16}$ La relación entre producciones artísticas y trabajo se reitera en las manos arrugadas que empuñan la manigueta, pero también en un nuevo proyecto de trabajo autogestivo que realiza prendas de vestir con estampas realizadas con serigrafía. Así, producción artística se entrelaza con reivindicaciones sociales y acciones políticas, resaltando desde la imagen las prácticas que las ponen en diálogo.

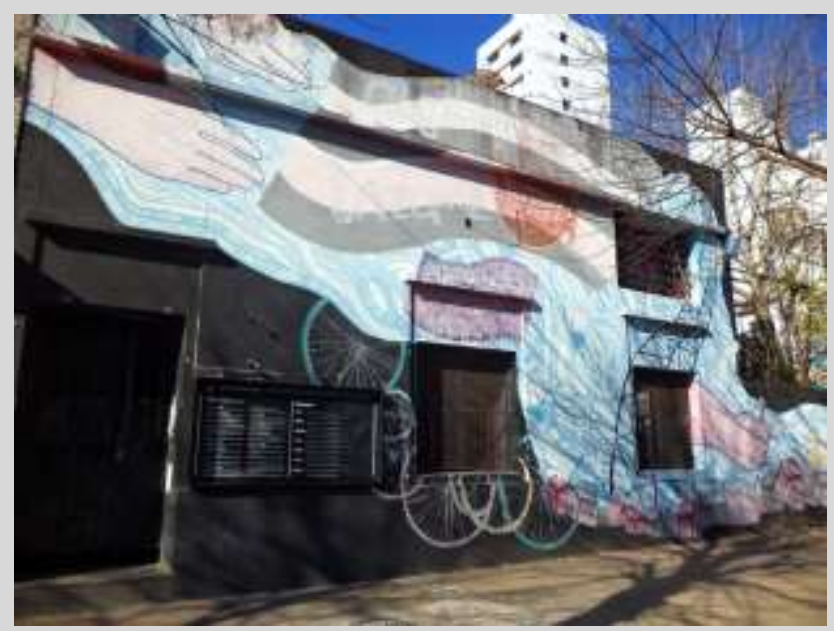

Figura 3: Mural realizado por Nelson Sosa y otros en el año 2012 (Foto del archivo personal de la autora).

\footnotetext{
${ }^{16}$ Radionauta es una FM comunitaria que se puede escuchar en el 106.3 del dial o en transmisión online. http://radionautafm.wordpress.com/
} 


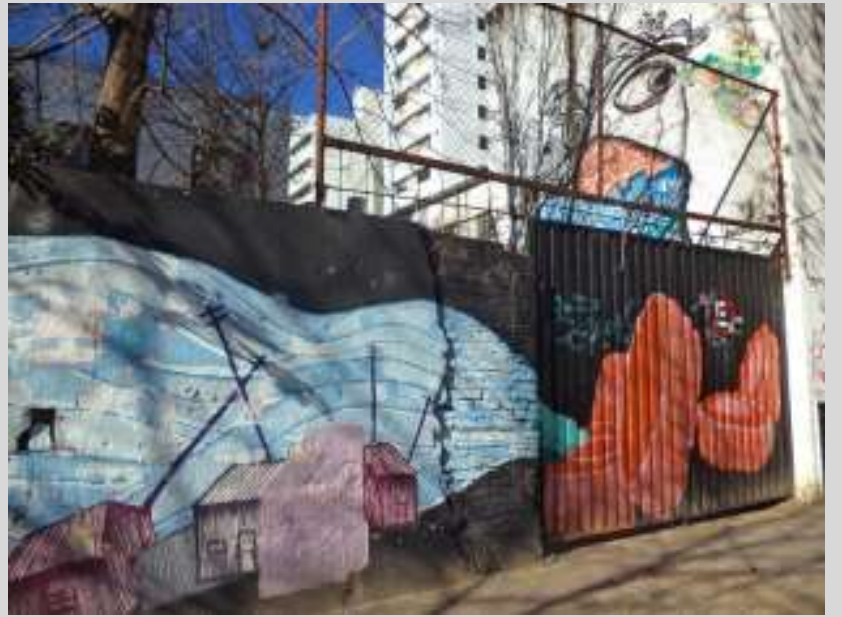

Figura 4: Mural realizado por Nelson Sosa y otros (Foto del archivo personal de la autora).

\section{Consideraciones finales}

En este trabajo se abordaron instancias de producción y acción colectiva, como es el caso del CSCOV, a partir de cómo sus prácticas proponen otros sentidos posibles sobre el trabajo y la cultura, a partir de la construcción de formas de sociabilidad disruptiva. "Esta confluencia genera un nuevo cosmos, intenta mostrar otra forma de pensar y hacer el trabajo, otras formas posibles de las relaciones sociales, en definitiva, de habitar el mundo". ${ }^{17}$

Se pudo observar que el CSCOV, como otros similares, son espacios que emergen en cierto contexto poscrisis con "nuevos significados y valores, nuevas prácticas, nuevas relaciones y tipos de relaciones" (Williams, 2000a, p. 145).

Como se describió anteriormente, estas prácticas se cristalizaron a través de los murales de su fachada, especies de manifiestos visuales que operaron en un doble sentido: hacia adentro, para reafirmar la pertenencia identitaria que aglutina al colectivo que activa el Centro Cultural y a todo el que sienta la pertenencia al espacio (partícipes indirectos, como pueden ser asistentes a los espectáculos, alumnos de los cursos y talleres, etc.); y hacia afuera, como señalamiento, expresión, manifiesto de cara a la ciudad, para que el transeúnte reconozca que no se trata de un edificio más en la uniformidad de la ciudad, y hacerse así visible como espacio diferenciado.

Dichos murales participan también de una nueva visualidad urbana que se empezó a gestar en los meses inmediatos posteriores al 2001, cuando las calles fueron copadas por diferentes manifestaciones de la creatividad y la visualidad como formas privilegiadas del reclamo social. Con el paso del tiempo y la recuperación económica e institucional, en algunos casos estas estéticas urbanas impulsaron otras demandas y

\footnotetext{
17 "La casa de tod@s". http://elmachete-fpds.blogspot.com.ar/2008/11/csc-olga-vzquez.html
} 
levantaron otras banderas, y en otros casos dejaron de ser necesariamente la expresión de un reclamo, para validarse como prácticas artísticas en sí mismas, logrando así en la actualidad la convivencia de diferentes formas del denominado arte urbano.

Entonces, lo que se manifiesta en estos murales va más allá de lo que muestran las imágenes en sí, e incluso más allá de las prácticas concretas al interior del CSCOV. Son parte de una pugna por los espacios en la ciudad, espacios de empoderamiento y espacios de visibilidad de prácticas socio-culturales disruptivas. En este sentido, más que como dispositivos de representación, los murales de la fachada se constituyen en dispositivos de construcción de otras realidades posibles y de formas de subjetivación disruptiva, entendiendo que las manifestaciones artísticas son políticas más allá de su contenido, pero también, y sobre todo, lo son por el dispositivo y soporte social del que son parte. Como sostiene Jacques Rancière, las prácticas del arte "[...] contribuyen a diseñar un paisaje nuevo de lo visible, de lo decible y de lo factible. Ellas forjan contra el consenso otras formas de 'sentido común', formas de un sentido común polémico" (Rancière, 2010, p. 77).

\section{Bibliografía}

Augé, M. (1993). Los no lugares, espacios del anonimato. Una antropología de la sobremodernida. Barcelona: Gedisa.

Aumont, J. (1992). La imagen. Barcelona. Bs. As. México: Ediciones Paidós.

Barbero, J. (2010). De los medios a las mediaciones. Comunicación, cultura y hegemonía. Rubí (Barcelona): Anthropos Editorial; México: Universidad Autónoma Metropolitana- Azcapotzalco.

Capasso, V. (2011). El espacio como encrucijada. Intervenciones artístico-políticas en la ciudad de La Plata. $1^{\circ}$ Congreso virtual sobre espacio "Abordajes del Espacio a través de una mirada multidisciplinar". Universidad de Tucumán.

Deleuze, G. (1990). ¿Qué es un dispositivo? En Deleuze, G.; Glucksmann, A.; Frank, M.; Balbier, E. y Otros. Michel Foucault filósofo. Barcelona: Gedisa.

Giunta, A. (2009). Poscrisis. Buenos Aires: Siglo XXI Editores.

Guattari, F. y Rolnik, S. (2006). Micropolítica, Cartografías del deseo. Madrid: Traficantes de Sueños.

Jáuregui, J. (2008). La ciudad en devenir: Economías informales/ espacios efímeros. En: Catálogo Post-It City. Ciudades Ocasionales. Barcelona: CCCB, SEACEX, Turner.

La Varra, G. (2008). El último espacio público de la ciudad contemporánea. En: Catálogo Post-It City. Ciudades Ocasionales. Barcelona: CCCB, SEACEX, Turner.

Lefebvre, H. (1969). El derecho a la ciudad. Barcelona: Ediciones Península.

Rancière, J. (2010). El espectador emancipado. Buenos Aires: Ediciones Manantial.

Svampa, M. (2005). La sociedad excluyente. La Argentina bajo el signo del neoliberalismo. Buenos Aires: Taurus.

Williams, R. (2000a). Marxismo y Literatura. Barcelona: Ediciones Península. 
Williams, R. (2000b). Palabras claves. Buenos aires: Visión.

Zibecchi, Raúl. (2003). Genealogía de la revuelta. Argentina: la sociedad en movimiento. La Plata: Nordan comunidad, Piedra Libre.

\section{Revistas}

Lechner, N. (2002). El capital social como problema cultural. Revista Mexicana de Sociología, vol. 64, No 2, México: UNAM.

Salomone, M \& Marsonte, P. (2011). Territorio urbano: Espacio para la vida vs espacio para el capital. La disputa por los terrenos del ferrocarril en Mendoza. Revista Herramienta N48, Año XV, Buenos Aires.

\section{Referencias electrónicas}

Entrevista al colectivo de arte Sienvolando. Por el Colectivo Indymedia La Plata. Disponible en:

http://argentina.indymedia.org/news/2008/06/610696.php [en línea 5 de mayo 2014]

García Canclini, N. (....). Ni folklórico ni masivo ¡Que es lo popular? Revista

Iberoamericana de Comunicación, ISSN 1696-2257, Disponible en Infoamérica:

http://www.infoamerica.org/documentos pdf/garcia canclinil.pdf [en línea 23 de mayo de 2014]

Guerreiro, L. (2010). Espacios de articulación, redes autogestivas e intercambios alternativos en la ciudad de Buenos Aires. Revista Otra Economía. Volumen 4. Número 6. Disponible en:

http://revistas.unisinos.br/index.php/otraeconomia/article/view/1184/345 [en línea 15 de marzo 2014].

Harvey, D. (2008). El derecho a la ciudad. Disponible en:

http://newleftreview.es/53 [en línea 11 de enero 2013].

"La casa de tod@s" Revista El Machete. Año 2008. Disponible en:

http://elmachete-fpds.blogspot.com.ar/2008/11/csc-olga-vzquez.html [en línea 4 de abril 2014]

Blog del Centro Social y Cultural Olga Vázquez. www.olgavazquez.blogspot.com.ar

Blog del colectivo Sienvolando www.sienvolando.blogspot.com.ar

Svampa, M. (2004). El devenir de las organizaciones piqueteras en Argentina. Publicado en Barataria, No 1, septiembre 2004, La Paz, Bolivia; y en Mouvements et pouvoirs de gauches en Amérique Latine, Alternative Sud, centre Tricontinental et Editions Syllepse, Volumen 12, No 2, 2005, Louvaine, Bélgica. Disponible en:

http://www.maristellasvampa.net/archivos/ensayo01.pdf [en línea 19 de junio de 20 